\title{
Cytosolic Delivery of Liposomally Targeted Proteins Induced by Photochemical Internalization
}

\author{
Marjan M. Fretz, ${ }^{1}$ Anders Høgset, ${ }^{2}$ Gerben A. Koning, ${ }^{3}$ Wim Jiskoot, ${ }^{1,4}$ and Gert Storm ${ }^{1,5}$
}

Received October 31, 2006; accepted January 18, 2007; published online May 31, 2007

\begin{abstract}
Purpose. The application of therapeutic proteins is often hampered by limited cell entrance and lysosomal degradation, as intracellular targets are not reached. By encapsulation of proteins into targeted liposomes, cellular uptake via endocytosis can be enhanced. To prevent subsequent lysosomal degradation and promote endosomal escape, photochemical internalization (PCI) was studied here as a tool to enhance endosomal escape. PCI makes use of photosensitising agents which localize in endocytic vesicles, inducing endosomal release upon light exposure.

Materials and Methods. The cytotoxic protein saporin was encapsulated in different types of targeted liposomes. Human ovarian carcinoma cells were incubated with the photosensitiser TPPS2a and liposomes. To achieve photochemical internalization, the cells were illuminated for various time periods. Cell viability was used as read-out. Illumination time and amount of encapsulated proteins were varied to investigate the influence of these parameters.

Results. The cytotoxic effect of liposomally targeted saporin was enhanced by applying PCI, likely due to enhanced endosomal escape. The cytotoxic effect was dependent on the amount of encapsulated saporin and the illumination time.

Conclusion. PCI is a promising technique for promoting cytosolic delivery of liposomally targeted saporin. PCI may also be applicable to other liposomally targeted therapeutic proteins with intracellular targets.
\end{abstract}

KEY WORDS: cytosolic delivery; endosomal escape; liposomes; photochemical internalisation; protein delivery.

\section{INTRODUCTION}

An increasing number of biomolecules, like proteins and nucleic acids, are being developed for therapeutic use. However, intracellular delivery of such macromolecules to their target sites present in the cytosol or nucleus is often inefficient. Their hydrophilic and charged nature together with their high molecular weight, make cell membrane passage difficult. Furthermore, these molecules often have poor pharmacokinetic and biodistribution properties and are highly susceptible to degradation by extra- and intracellular enzymes. Therefore, delivery systems, like liposomes, are

\footnotetext{
${ }^{1}$ Department of Pharmaceutics, Utrecht Institute for Pharmaceutical Sciences (UIPS), Utrecht University, P.O. Box 80082, 3508 TB, Utrecht, The Netherlands.

${ }^{2}$ PCI Biotech AS, Hoffsveien 48, N-0377, Oslo, Norway.

${ }^{3}$ Department of Radiation, Radioisotopes and Reactors (R3), Faculty of Applied Sciences, Delft University of Technology, Delft, The Netherlands.

${ }^{4}$ Division of Drug Delivery Technology, Leiden/Amsterdam Center for Drug Research (LACDR), Leiden University, Leiden, The Netherlands.

${ }^{5}$ To whom correspondence should be addressed. (e-mail: G.Storm@ pharm.uu.nl)
}

required to improve the therapeutic efficacy of labile macromolecular drugs. Liposomes can improve pharmacokinetics, provide protection from degradation, mediate targeting to the pathological site and facilitate uptake by the target cells $(1,2)$. However, although pharmacokinetics, tissue distribution, and cellular uptake can be improved using (targeted) liposomes, the liposomal drug usually ends up in the endo- and lysosomes, where both the liposome particles as well as the encapsulated macromolecules are subject to degradation $(3,4)$.

Therefore, endosomal escape of liposome-encapsulated macromolecules is a vital issue in drug delivery research. In the liposome field, various approaches are being investigated to realize endosomal escape of liposomal contents. One approach makes use of lipids with $\mathrm{pH}$-dependent membranedestabilizing properties. Upon acidification, as occurring in the endosomal/lysosomal compartment where the targeted liposomes end up after internalization by target cells, these lipids undergo a phase transition and when incorporated in the liposomal membrane, they promote fusion with and/or destabilization of the endosomal membrane. The most commonly used lipid in this context is dioleoyl phosphatidyl ethanolamine (DOPE) in combination with acidic lipids such as cholesteryl hemisuccinate (CHEMS), oleic acid (OA), $\mathrm{N}$-palmitoyl homocysteine (PHC) and dipalmitoyl succinyl glycerol (DSPG). This approach is adequately reviewed in 
reference (5). Lee et al. reported on the successful cytosolic delivery of liposomal contents by co-encapsulation of the pore forming protein listeriolysin $\mathrm{O}$ (LLO) in $\mathrm{pH}$-sensitive liposomes. This delivery system mimics the intracellular invasion strategy of the pathogen Listeria monocytogenes which uses LLO to escape from the endosomes (6-8). Coencapsulation of a fusogenic peptide derived from the influenza virus hemagglutinin resulted in efficient cytosolic delivery of liposomal diphtheria toxin A-chain as reported by Mastrobattista et al. (9). Kakuda et al. demonstrated that the insertion of cholesterol derivatized GALA-peptide into the liposomal bilayer also stimulated release of liposomal contents into the cytosol (10).

Recently a new technique, referred to as photochemical internalization (PCI) has been reported to be useful for the promotion of endosomal escape of macromolecules or particulate systems (reviewed in (11)). The technique is based on the specific localization of a photosensitiser in endosomal membranes. Photosensitisers with an amphiphilic nature will, when added to cells, localize in the plasma membranes and, upon endocytosis, accumulate primarily in endosomal membranes. Including a photosensitizer free incubation period in the experimental PCI protocol will ascertain localization of the photosensitizer predominantly in the endosomal membranes. Upon illumination, highly reactive singlet oxygen species are formed which damage the endosomal membranes and make it permeable for endocytosed material. Upon illumination release of lysosomal enzymes into the cytosol was observed without extensive cell death (12).

The plant toxins gelonin and saporin, members of the type I ribosome-inactivating protein family, lack specific domains for cell entrance and if they are taken up via endocytosis, they will be degraded within the endosomal/ lysosomal pathway. However, if they are delivered into the cytoplasm, their potent inhibitory effect on the cellular protein synthesis results in severe cytotoxicity (13). Therefore, these macromolecules are useful for demonstrating the occurrence of endosomal escape.

The recently introduced technique PCI was applied for the cytosolic delivery of saporin via liposomes. Saporin was encapsulated into different types of liposomes, designed to deliver the toxin into EGF-receptor positive human ovarian cancer cells. To stimulate cellular uptake, positively charged and EGF-receptor targeted liposomes were employed. As cytotoxic activity of liposomal saporin was only observed in combination with PCI, it is demonstrated here for the first time that the combination of the use of targeted liposomes with PCI is a valuable approach for the cytosolic delivery of liposome-entrapped proteins.

\section{EXPERIMENTAL METHODS}

\section{Materials}

Egg-phosphatidylcholine (EPC) and 1,2-distearoyl-glycero-3-phosphoethanolamine- $N$-[poly(ethylene glycol)2000] $\left(\mathrm{PEG}_{2000}\right.$-DSPE) were obtained from Lipoid $\mathrm{GmbH}$ (Ludwigshafen, Germany). Maleimide-PEG 2000 -DSPE (MalPEG-DSPE) was obtained from Shearwater Polymers (Huntsville, AL, USA). 1,2-dioleoyl-3-trimethylammoniumpropane chloride salt (DOTAP) was purchased from Avanti Polar Lipids (Alabaster, AL, USA). Cholesterol (CHOL),
S-acetylthioglycolic acid N-hydroxysuccinimide ester (SATA), XTT sodium salt and saporin were purchased from SigmaAldrich Co. (St. Louis, MO, USA). Titriplex III (EDTA) was obtained from Merck (Darmstadt, Germany). Hepes was purchased from Acros (Geel, Belgium). Hydroxylamine hydrochloride was from ICN Biomedicals (Aurora, $\mathrm{OH}$, USA). ${ }^{125} \mathrm{I}$ was purchased from Amersham Biosciences (Diegem, Belgium).

1,1'-dioctadecyl-3,3,3', $3^{\prime}$-tetramethylindocarbocyanine, 4-chlorobenzenesulfonate sulfonate salt (DiD) was obtained from Molecular Probes Europe BV (Leiden, The Netherlands). Murine monoclonal antibody mAb425 of isotype $\operatorname{IgG} 2 \mathrm{~b}$, directed against the human epidermal growth factor receptor (EGFR) was kindly donated by Merck KGaA (Darmstadt, Germany). Irrelevant isotype matched murine monoclonal antibody directed against the influenza virus HA (clone 12CA5) was kindly donated by Dr. E. Boot (Immunology Division, Department of Infectious Diseases and Immunology, Utrecht University, Utrecht, The Netherlands).

The photosensitiser LumiTrans ${ }^{\mathrm{TM}}$ (tetraphenylporphine disulfonate, $\operatorname{TPPS}_{2 \mathrm{a}}$ ) was a generous gift from PCI Biotech (Oslo, Norway).

\section{Cell Culture}

The human ovarian carcinoma cell line NIH:OVCAR-3 was obtained from the ATCC (Manassas, USA). The cells were cultured in Dulbecco's modified Eagle's medium containing $3.7 \mathrm{~g} / \mathrm{l}$ sodium bicarbonate, $4.5 \mathrm{~g} / \mathrm{l} \mathrm{L}$-glucose and supplemented with L-glutamine $(2 \mathrm{mM}), 10 \%(\mathrm{v} / \mathrm{v})$ fetal calf serum (FCS), penicillin (100 IU/ml), streptomycin $(100 \mu \mathrm{g} /$ $\mathrm{ml})$ and amphotericin $\mathrm{B}(0.25 \mu \mathrm{g} / \mathrm{ml})$ at $37^{\circ} \mathrm{C}$ with $5 \% \mathrm{CO}_{2}$ in humidified air. All cell-culture related material was obtained from Gibco (Grand Island, NY, USA).

\section{Liposome Preparation and Characterization}

The solvent evaporation/hydration method was used to prepare liposomes. Briefly, EPC, CHOL, PEG $_{2000}-\mathrm{DSPE}$ and maleimide-PEG 2000 -DSPE (molar ratio1.85:1.00:0.09:0.06) or EPC, CHOL and DOTAP (molar ratio 4:1:1) were dissolved in chloroform/methanol $(2: 1 \mathrm{v} / \mathrm{v})$. For FACS analysis, 0.1 mol\% DiD was added as fluorescent marker. After evaporation of the solvent, the lipid film was hydrated with a solution of $0.5 \mathrm{mg} / \mathrm{ml}$ or $0.1 \mathrm{mg} / \mathrm{ml}$ saporin in Hepes buffered saline (HBS; $10 \mathrm{mM}$ Hepes, $137 \mathrm{mM} \mathrm{NaCl}, \mathrm{pH}$ 7.4). The liposomes were sized to $150 \mathrm{~nm}$ by extrusion using a Lipex high pressure extruder (Northern Lipids, Vancouver, Canada). Non-encapsulated saporin was removed by size exclusion chromatography using Separose CL-4B (Amersham Pharmacia Biotech, Uppsala, Sweden).

The monoclonal antibody mAb425 and the irrelevant isotype antibody were modified with SATA to introduce sulfhydryl groups randomly as described previously (14). In short, an 8-fold molar excess of SATA dissolved in DMF was added to the antibody solution (1/10 of volume) and incubated for $45 \mathrm{~min}$ at room temperature. The non-coupled SATA was removed using Vivaspin columns (MWCO 50,000 Da, Vivascience, Hannover, Germany). The sample was centrifuged three times for $15 \mathrm{~min}$ at $5,500 \mathrm{rpm}$ at $4{ }^{\circ} \mathrm{C}$ and washed with HBS pH 7.4. 
Before coupling of the antibody to the maleimide-derivatized PEG-DSPE present on the liposome surface, the SATAgroup was activated using a hydroxylamine solution $(0.5 \mathrm{M}$ Hepes, 0.5 M hydroxylamine $\mathrm{HCl}$ and $0.25 \mathrm{mM}$ EDTA; $\mathrm{pH} 7.0$ ) for $1 \mathrm{~h}$ at room temperature. Coupling of the antibody to the maleimide-PEG-DSPE present on the liposomal surface occurred overnight at $4^{\circ} \mathrm{C}$. Non-coupled antibody was removed by size exclusion chromatography using Separose CL-4B.

The liposomes were characterized with respect to size using dynamic light scattering, phospholipid content according to Rouser (15) and amount of saporin encapsulated using ${ }^{125} \mathrm{I}$ determination.

\section{Labeling of Saporin with ${ }^{125} \mathrm{I}$}

Saporin was labelled with ${ }^{125} \mathrm{I}$ using Iodobeads (Pierce, Rockford, IL, USA). $5 \mathrm{MBq}$ of a ${ }^{125}$ I-solution in $0.01 \mathrm{M}$ $\mathrm{NaOH}(370 \mathrm{MBq} / 100 \mu \mathrm{l})$ was diluted in $200 \mu \mathrm{l} \mathrm{HBS} \mathrm{pH} 7.0$ and incubated with two Iodobeads for $5 \mathrm{~min}$ at room temperature. Subsequently, $1 \mathrm{ml}$ of a saporin solution (1 $\mathrm{mg} / \mathrm{ml}$ in water) was added and incubated for an additional $20 \mathrm{~min}$ at room temperature. Next, saporin and unbound ${ }^{125} \mathrm{I}$ were separated on a PD-10 column (Amersham Pharmacia Biotech) using HBS pH 7.0 as an eluent. Specific activity was determined by measuring activity on a Wallac 1480 "Wizard 3" sodium iodide counter and by detecting the UV absorbance at $280 \mathrm{~nm}$ using a Shimadzu UV-1601 spectrophotometer. The specific activity was $1.6 \mathrm{MBq} / \mathrm{mg}$ protein.

\section{Binding Studies}

OVCAR-3 cells were detached from the culture flask by trypsin/EDTA solution $(0.05 \%(\mathrm{w} / \mathrm{v})$ trypsin and $0.02 \%(\mathrm{w} / \mathrm{v})$ EDTA in PBS). Cells, $(100,000)$ were incubated for $1 \mathrm{~h}$ with fluorescently labelled liposomes at $4^{\circ} \mathrm{C}$. Cells were washed twice by centrifugation $\left(300 \times g, 5 \mathrm{~min}, 4^{\circ} \mathrm{C}\right)$. Flow cytometry analysis was performed using a FACScalibur (Beckton\& Dickinson, Mountain View, CA, USA) and data were analysed using WinMDI 2.8 software, which was kindly provided by Joseph Trutter.

\section{Cellular Uptake of Liposomal Saporin}

OVCAR-3 cells were seeded $\left(10^{5}\right.$ cells/well) in 6-well plates and cultured overnight prior to the experiment. The cells were incubated for $18 \mathrm{~h}$ with saporin-liposomes $(50 \mathrm{nmol}$ liposomal lipid). After three washing steps using PBS, the cells were subsequently chased for $4 \mathrm{~h}$ with liposome free medium. After washing, the cells were lysed with a $1 \%$ Triton X-100 solution (w/v in water) and frozen to $-20^{\circ} \mathrm{C}$. The thawed cell lysate was used for analysis on the Wallac sodium iodide counter.

\section{Efficacy Studies}

OVCAR-3 cells $\left(5 \times 10^{3}\right.$ cells/well) were seeded into 96well plates and cultured overnight prior to the experiment. Culture medium was removed and fresh culture medium was added containing either liposomes, photosensitiser or both. The photosensitiser was always added at a final concentration of $0.5 \mu \mathrm{g} / \mathrm{ml}$, while the liposome concentration varied. After $18 \mathrm{~h}$, liposomes and/or photosensitiser were removed and the

cells were incubated for $4 \mathrm{~h}$ with fresh culture medium before $75 \mathrm{~s}$ of illumination with the LumiSource (Osram 18W/67 with light intensity $7 \mathrm{~mW} / \mathrm{cm}^{2}$, PCI Biotech, Oslo, Norway). Cells were incubated for another $48 \mathrm{~h}$ before the cell viability was measured using the XTT assay as previously described (16).

\section{Effect of Illumination Time}

OVCAR-3 cells were incubated with $0.1 \mu \mathrm{M}$ saporinliposomes and $0.5 \mu \mathrm{g} / \mathrm{ml}$ photosensitiser for $18 \mathrm{~h}$ and subsequently for $4 \mathrm{~h}$ with complete culture medium. The cells were illuminated for 45,75 or $120 \mathrm{~s}$. Cell viability was assessed with the XTT assay $48 \mathrm{~h}$ after illumination.

\section{Contribution of PDT to Cell Death}

OVCAR-3 cells were incubated with $0.1 \mu \mathrm{M}$ saporinliposomes and $0.5 \mu \mathrm{g} / \mathrm{ml}$ photosensitiser for $18 \mathrm{~h}$ and subsequently for $4 \mathrm{~h}$ with complete culture medium. The cells were illuminated for 45,75 or $120 \mathrm{~s}$. Cell viability was assessed with the XTT assay $48 \mathrm{~h}$ after illumination. The contribution of photodynamic therapy (PDT) effects to cell death was calculated with the following formulas:

\section{Total Cell Viability $(T C V)$ \\ $=\left(\frac{\text { Absorbance }(\text { treated with liposomes }, \text { photosensitizer and light })}{\text { Absorbance }(\text { non }- \text { treated })}\right)$ $\times 100 \%$}

Cell Viability after PDT $(C V P D T)$
$=\left(\frac{\text { Absorbance }(\text { treated with photosensitizer and light })}{\text { Absorbance }(\text { non }- \text { treated })}\right)$
$\quad \times 100 \%$

Cell death PDT $=100-C V P D T$

Cell death PCI $=100-$ Cell death PDT $-T C V$ $\begin{aligned} \text { Total cell death } & =\text { Cell death PDT }+ \text { Cell death PCI } \\ & =100-T C V\end{aligned}$

Contribution of PDT to cell death

$$
=\left(\frac{\text { Cell death PDT }}{\text { Total Cell death }}\right) \times 100 \%
$$

Contribution of PCI to cell death

$$
=\left(\frac{\text { Cell death PCI }}{\text { Total Cell death }}\right) \times 100 \%
$$




\section{RESULTS AND DISCUSSION}

\section{Liposome Characteristics}

The following liposome types were used to deliver saporin into human ovarian carcinoma cells (OVCAR-3): 1. Cationic liposomes (DOTAP-L) were prepared by incorporation of the positively charged lipid DOTAP $(17 \mathrm{~mol} \%$ of total lipid) into EPC/CHOL liposomes. The cationic nature of these liposomes mediates a strong affinity for negatively charged cell membranes (17). 2. Epidermal growth factor receptor (EGFR) targeted PEG-liposomes (EGFR-L) were prepared to target to the EGFR by coupling an anti-EGFR antibody to the distal end of the PEG-chains. The EGFR is overexpressed in several tumor cell lines and is an internalising receptor, which makes it an attractive target for drug delivery (18). As already shown by former studies in our laboratory, EGFR-L can be used to specifically target OVCAR-3 cells (9). 3. PEGliposomes (PEG-L) without an antibody attached were used as a control. Due to the PEG-layer surrounding these liposomes, the cellular association and uptake by OVCAR-3 cells is low as shown previously $(9,19)$.

All liposome types used had a particles size between 140 and $160 \mathrm{~nm}$ and a polydispersity index $<0.2$, which indicates a

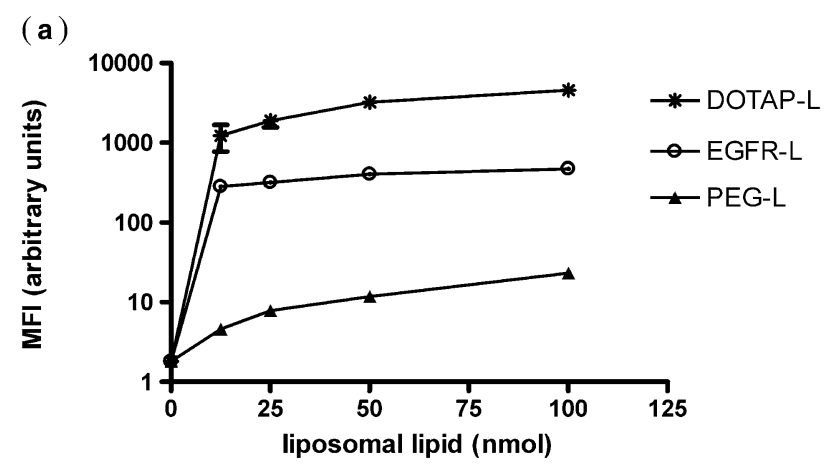

(b)

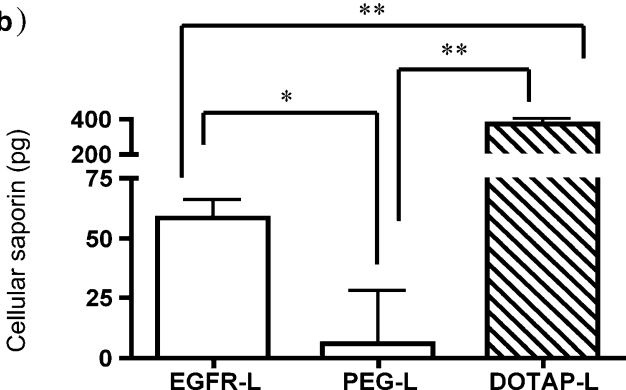

Fig. 1. Cellular binding and uptake of different liposome types containing saporin. a Binding of different types of saporin-liposomes to OVCAR-3 cells. Fluorescently labelled liposomes were incubated for $1 \mathrm{~h}$ at $4^{\circ} \mathrm{C}$ with OVCAR-3 cells, washed and analysed by flow cytometry. Data represents mean $\pm \mathrm{SD}(n=3)$. Error bars are within plot symbol when not visible. Statistical analysis was performed using a $F$-test. All curves are significantly different $(P<0.0001)$. b Cellular ${ }^{125}$ I-saporin after $18 \mathrm{~h}$ incubation with liposomal ${ }^{125}$ I-saporin followed by $4 \mathrm{~h}$ chase period with liposome free medium. Data represent mean $\pm \mathrm{SD}(n=3)$. Statistical analysis was performed using a one-way ANOVA $(P<0.0001)$ followed by Newman-Keuls post-hoc multiple comparison test $(* P<0.05$ and $* * P<0.001)$.
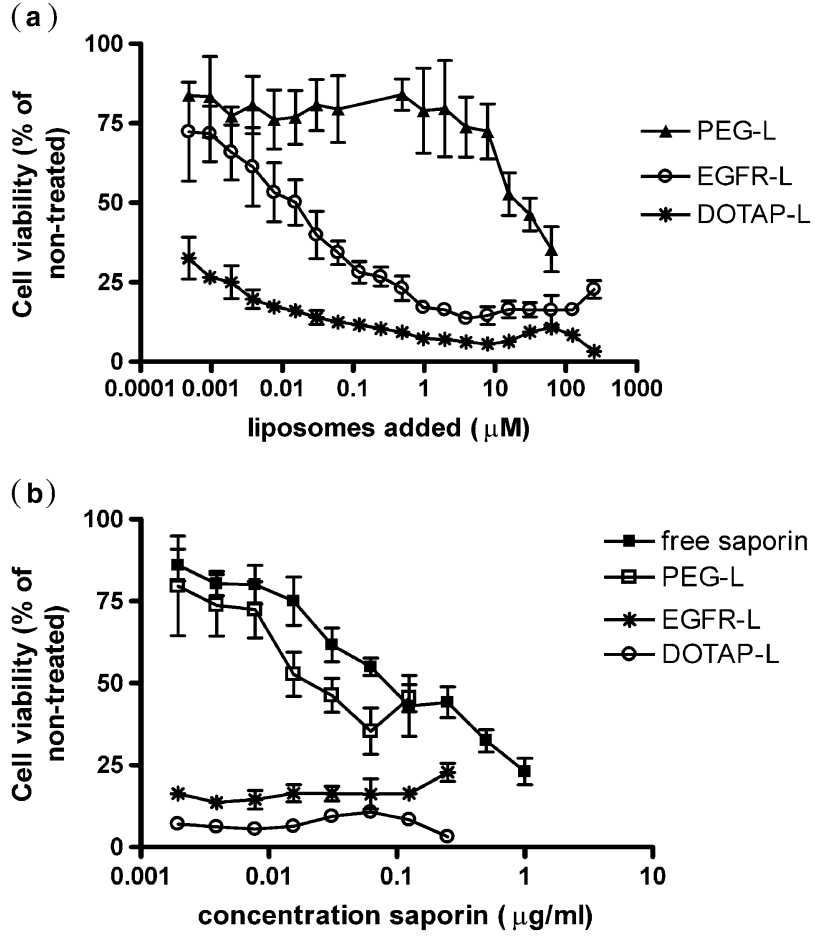

Fig. 2. Effect of PCI on cytotoxicity after exposure to liposomal saporin a. Comparison of liposomal saporin with free saporin in combination with PCI b. OVCAR-3 cells were incubated for 18 $\mathrm{h}$ with liposomes and photosensitiser, subsequently washed away and incubation was continued for $4 \mathrm{~h}$ before the onset of $75 \mathrm{~s}$ of illumination. Forty-eight hours after illumination, the cell viability was assessed with the XTT assay. Data represent mean \pm SD $(n=4)$. Error bars are within plot symbols when not visible. Statistical analysis was performed on Fig. 2a using an $F$-test. Curves are significantly different $(P<0.0001)$.

narrow size distribution. As quantified by ${ }^{125}$ I-saporin determination, the encapsulated amount of saporin varied between 0.3 and $0.9 \mu \mathrm{g} / \mu \mathrm{mol}$ lipid which correspond to an encapsulation efficiency varying between 3.0 and $5.4 \%$. The fluorescent bilayer marker DiD was incorporated $(0.1 \mathrm{~mol} \%)$ in case of experiments designed to monitor the cellular binding of the liposomes.

\section{Cellular Binding and Uptake of Saporin-Liposomes}

The binding of the different liposome types to OVCAR-3 cells was investigated by flow cytometry using the fluorescent bilayer marker DiD (Fig. 1a). The highest level of cellular association was observed in case of the positively charged DOTAP-L. Electrostatic interaction between the positively charged DOTAP-L and negatively charged cell membranes results in a strong binding. The use of targeted EGFR-L resulted in a 20-60 fold increased fluorescence signal compared to nontargeted PEG-L. This indicates that the EGFR-targeted liposomes do interact with the EGF-receptor expressed on the OVCAR-3 cells and that targeting the EGF-receptor may be useful for increasing the delivery of liposomal proteins. The coupling of an irrelevant isotype match antibody to liposomes results in a degree of cell binding of the liposomes which is comparable to that of non-targeted PEG-liposomes. Further- 

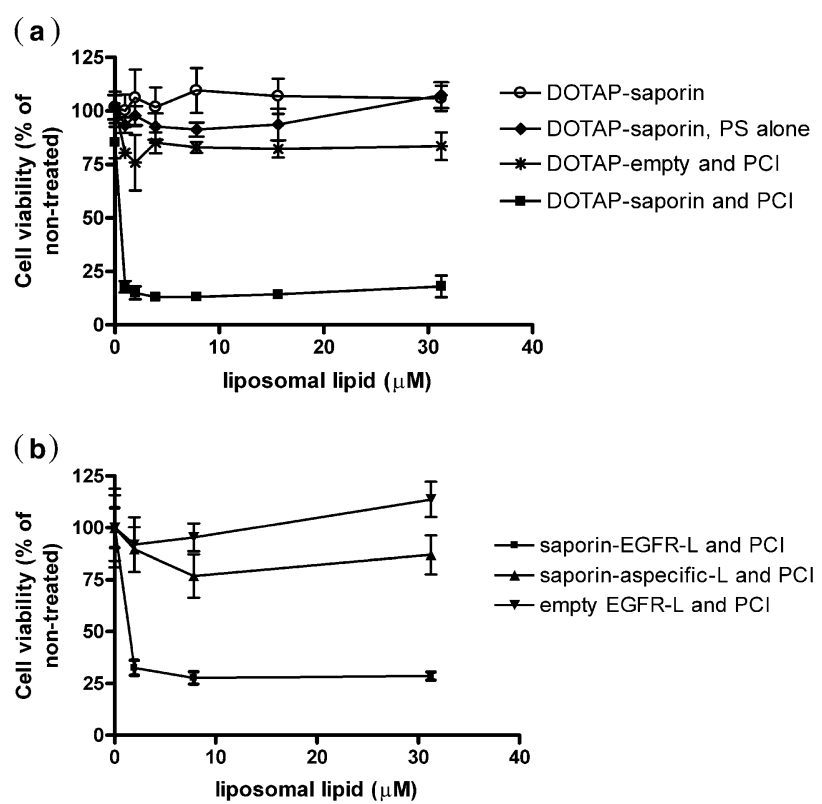

Fig. 3. Cytotoxicity after different control treatments. a OVCAR-3 cells were incubated with saporin-containing (empty circle, filled diamond, filled square) or empty (asterisk) DOTAP-L in the presence (filled diamond, asterisk, filled square) or absence (empty circle) of photosensitiser for $18 \mathrm{~h}$, subsequently washed away and incubation was continued for $4 \mathrm{~h}$ before $75 \mathrm{~s}$ illumination (asterisk, filled square). Cell viability was assessed $48 \mathrm{~h}$ after illumination with the XTT assay. b OVCAR-3 cells were incubated with saporincontaining (filled square, filled triangle) or empty (filled upside down triangle) immunoliposomes and photosensitizer for $18 \mathrm{~h}$, subsequently washed and incubation was continued for $4 \mathrm{~h}$ before $75 \mathrm{~s}$ illumination. Cell viability was assessed $48 \mathrm{~h}$ after illumination with the XTT assay. The liposomes contained either an antibody targeting the EGFR (filled square, filled upside down triangle) or an aspecific antibody (filled triangle). Data represents mean $\pm \mathrm{SD}(n=4)$. Error bars are within plot symbols when not visible.

more, competition by adding excess of free antibody could partially reduce cell binding of the EGFR-L (results not shown).

Additionally, we measured the amount of cellular saporin after incubation at $37^{\circ} \mathrm{C}$ using ${ }^{125}$ I-labeled saporin. OVCAR-3 cells were incubated with DOTAP-L, EGFR-L or PEG-L, all containing ${ }^{125} \mathrm{I}$-labeled saporin and the results shown in Fig. 1b correspond to the cell-binding data in Fig. 1a. The extent of liposome-mediated delivery of saporin to the cells decreased in the following order: DOTAP-L > EGFR-L > PEG-L. It is known that (targeted) liposomes can be taken up by endocytosis, which in this case most probably results in the degradation of the liposomal saporin in the lysosomes (20). To 'rescue' saporin from degradation, we included PCI in the treatment to achieve endosomal release of the liposomal saporin.

\section{Efficacy Studies}

Recent studies have shown that the PCI technique is capable to induce selective release of material from the endosomes into the cytoplasm. Selbo et al. demonstrated that the use of PCI enhanced the potency of the plant toxin gelonin in inhibiting cellular protein synthesis by a factor of 300 (21). In addition, the low-molecular weight drug bleo- mycin (22), antigenic peptides (23), immunotoxins $(24,25)$, peptide nucleic acids (26) and even colloidal carriers for gene delivery (27-29) have been successfully delivered into the cytosol via PCI. These agents generally are not able to reach their intracellular target site efficiently, due to lack of capability to pass cellular membranes and/or the occurrence of degradation within endocytic vesicles. The endosomal release of liposomal drugs enabled by PCI has not been demonstrated yet. As liposomes have a prominent place in the arsenal of advanced drug delivery systems developed over the years, it is important to evaluate whether PCI can be employed to further improve the efficacy of liposomal drug formulations.

To investigate whether the PCI technique is able to enhance the cytosolic delivery of liposomal proteins in vitro, OVCAR-3 cells were incubated with different types of saporin-liposomes and/or the photosensitiser $\mathrm{TPPS}_{2 \mathrm{a}}$ and subsequently illuminated to activate the photosensitiser. Since the ribosome-inactivating protein saporin will only have cytotoxic properties when delivered in its active form into the cytosol, cell viability was chosen as read-out (13). Fig. 2a shows the cell viability of OVCAR-3 cells after incubation with the different types of liposomes and photosensitiser, followed by illumination. Both DOTAP-L as well as EGFR-L strongly decreased cell viability compared to PEG-L, with DOTAP-L being superior over EGFR-L. Even at the lowest concentration added $\left(0.5 \times 10^{-3} \mu \mathrm{M}\right.$ liposomes $)$ only $30 \%$ of the cells survived the treatment with saporincontaining DOTAP-L in combination with PCI, compared to $75 \%$ survival when EGFR-L are used at this concentration. Saporin in PEG-L was cytotoxic only at concentrations higher than $10 \mu \mathrm{M}$, which is at a level of four orders of magnitude higher than for EGFR-L and five orders of magnitude higher than for DOTAP-L. When the cytotoxic effect of saporin-liposomes in combination with PCI is compared with that of free saporin combined with PCI (Fig. 2b), it is obvious that both DOTAP-L and EGFR-L are by far more cytotoxic due to the enhanced cytosolic delivery of saporin. Combination of PCI with free saporin was comparable to that of saporin-containing PEG-L combined

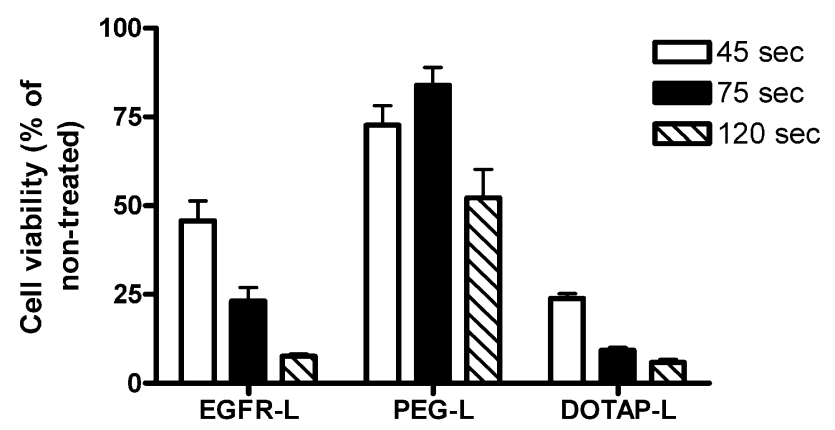

Fig. 4. Effect of illumination time on cytotoxicity after treatment with saporin-liposomes with PCI. OVCAR-3 cells were incubated with $0.1 \mu \mathrm{M}$ saporin-containing liposomes and $0.5 \mu \mathrm{g} / \mathrm{ml}$ photosensitiser for $18 \mathrm{~h}$, subsequently washed away and incubation was continued for $4 \mathrm{~h}$ before the onset of illumination $(45,75$ or $120 \mathrm{~s})$. Forty-eight hours after illumination, the cell viability was assessed with the XTT assay. Data represents mean \pm SD $(n=4)$. Statistical analysis was performed using an $F$-test. Data is significantly different $(P<0.05)$. 

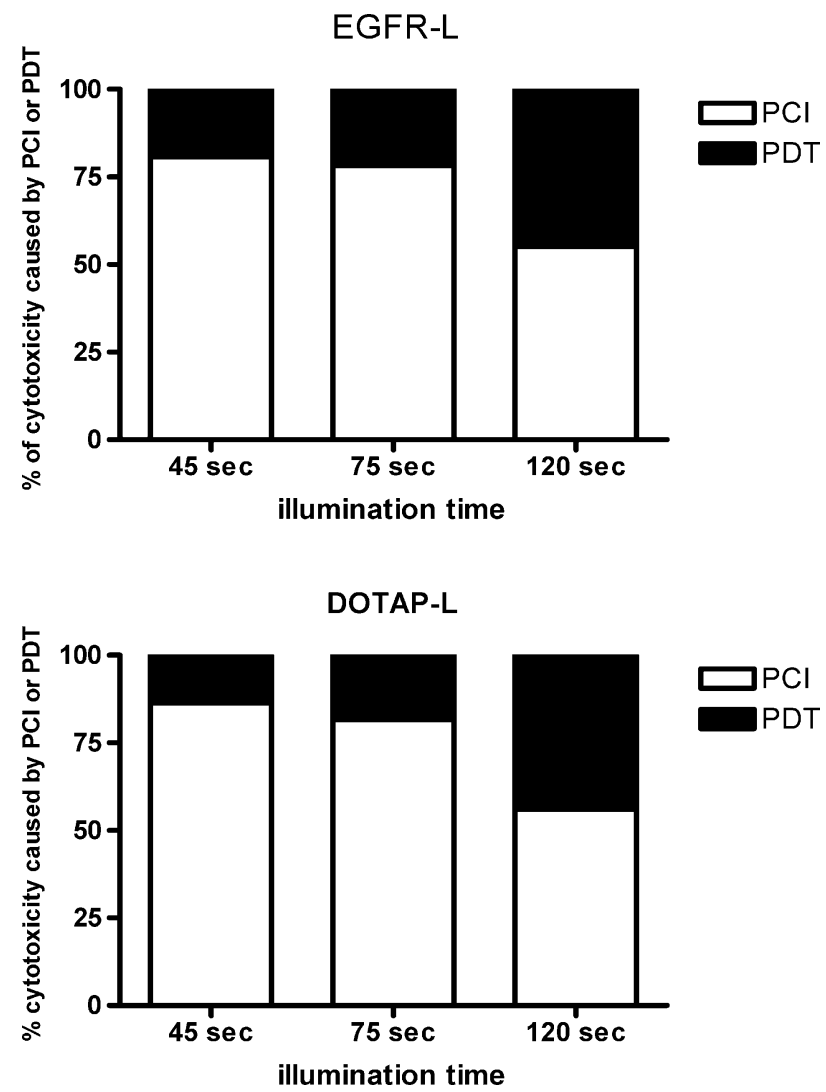

Fig. 5. Relative contribution of PDT and PCI to cytotoxicity. OVCAR-3 cells were incubated with $0.1 \mu \mathrm{M}$ saporin-containing liposomes and $0.5 \mu \mathrm{g} / \mathrm{ml}$ photosensitiser for $18 \mathrm{~h}$, subsequently washed away and incubation was continued for $4 \mathrm{~h}$ before the onset of illumination $(45,75$ or $120 \mathrm{~s})$. Forty-eight hours after illumination, the cell viability was assessed with the XTT assay. PDT effect was calculated as percentage cytotoxicity caused by photosensitizer and illumination treatment alone. The cytotoxicity caused by PCI was calculated by subtraction the PDT attribution from the total cytotoxicity. Data represents mean \pm SD $(n=4)$.

with PCI, indicating limited cytosolic delivery of saporin yielding sub-threshold levels for cytotoxicity.

To demonstrate that the use of PCI is essential for cytosolic delivery of saporin, different control experiments were carried out. Fig. 3a demonstrates that only the combination of saporin-liposomes (DOTAP-L) with both photosensitiser and illumination (PCI) has cytotoxic properties. Empty DOTAP-L, i.e. devoid of saporin, were examined and did not show any cytotoxicity in combination with PCI. In addition, when saporin-containing DOTAP-L were used in combination with only photosensitiser or only illumination or neither of those, no decrease in cell viability was seen (data not shown in case of saporin-containing liposomes in combination with illumination, but without photosensitiser). Analogous control experiments using of saporin-containing EGFR-L showed similar results (data not shown). Fig. 3b shows that saporin-liposomes with an irrelevant isotype control antibody in combination with PCI did not decrease the cell viability. This result demonstrates that the active targeting of the liposomes using an anti-EGF-receptor antibody is an essential requirement for these liposomes to deliver saporin to the cytosol in combination with PCI. In addition, empty EGFR-L in combination with PCI did not cause any cytotoxicity indicating that the cytotoxicity of saporin containing EGFR-L with PCI is not caused by an EGF-receptor mediated cell death cascade.

\section{Effect of Illumination Time}

As illumination time may play a critical role, its effect on the cytotoxic properties of saporin-liposomes in combination with PCI was assessed. The effect of the illumination time on cytotoxicity is shown in Fig. 4. A general trend can be observed: the longer the illumination time, the stronger the cytotoxic effect. This observation corresponds to observations done by others using PCI in combination with the plant toxin gelonin $(21,23)$. Routinely, we used $75 \mathrm{~s}$ as illumination time in our experiments.

\section{Contribution of PDT to Cytotoxicity}

Photodynamic therapy (PDT) is a treatment that uses photosensitising agents to kill tumor cells. Like in PCI, reactive oxygen species are generated upon illumination of the photosensitiser which damage cellular organelles like mitochondria with cell death as an end result. Besides damage to tumor cells, tumor associated vasculature can be damaged. Furthermore, an immune response against tumor cells can be induced leading to indirect tumor cell death $(30,31)$. To address the question to which extent cell death is caused by the photosensitiser and illumination alone (i.e., a PDT effect) and to which extent by the release of saporin from the endosomes induced by the photosensitiser and illumination (i.e., PCI), the relative contribution of a PDT effect on the observed cytotoxicity was studied (Fig. 5). The graphs show that the PDT effect is approximately $20 \%$ for the shorter illumination times (45 or $75 \mathrm{~s}$ ). On prolonged illumination $(120 \mathrm{sec})$ the PDT contribution to cell death is increased to almost $50 \%$. The total cell viability decreases upon longer incubation (Fig. 4), which is mainly caused by

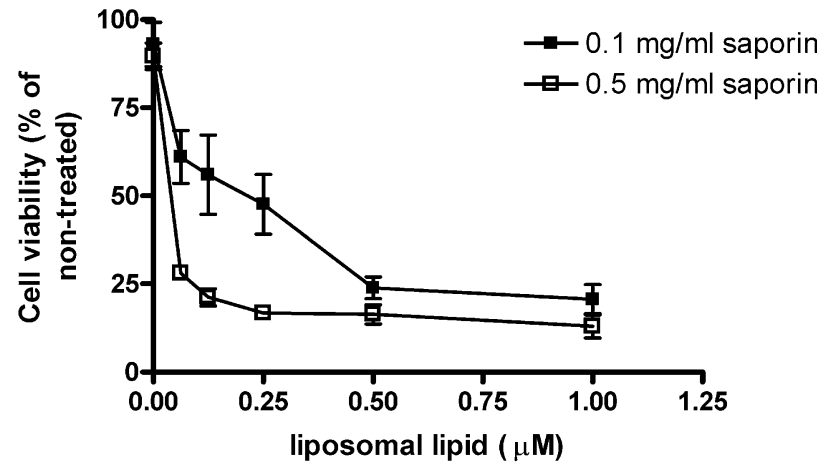

Fig. 6. Effect of encapsulated amount of saporin. OVCAR-3 cells were incubated with DOTAP-L, which were prepared with a hydration medium containing 0.1 or $0.5 \mathrm{mg} / \mathrm{ml}$ saporin in the presence of photosensitiser for $18 \mathrm{~h}$, washed away and incubation continued for $4 \mathrm{~h}$ before the onset of the $75 \mathrm{~s}$ illumination. Cell viability was assessed $48 \mathrm{~h}$ after illumination. Data represent mean \pm $\mathrm{SD}(n=4)$. Error bars are within plot symbols when not visible. Statistical analysis was performed using an $F$-test. Curved are significantly different $(P<0.01)$. 
the more pronounced PDT effect at longer illumination times. Thus, efficient PCI is already achieved at the shorter illumination times, without considerable PDT effect. Upon prolonged illumination, PDT effects become more prominent. Obviously, the occurrence of an additional PDT effect in cancer treatment is beneficial as it will strengthen the PCImediated anti-tumor effect.

\section{Effect of Amount of Encapsulated Saporin}

To investigate whether the amount of encapsulated protein in the liposomes influences the PCI-promoted cytoxicity, liposomes were prepared containing different amounts of saporin. The results presented in Fig. 6 indeed show that liposomes prepared by hydrating the lipid film either in 0.1 or $0.5 \mathrm{mg} / \mathrm{ml}$ saporin, do differ substantially in cytotoxic effect when combined with PCI up to a liposomal lipid concentration of $0.5 \mu \mathrm{M}$. Above this concentration similar cytotoxicity was observed.

The estimated EC50 values are 0.11 and $0.005 \mu \mathrm{M}$ for the low and high saporin-containing liposomes, respectively. These results indicate that both the amount of encapsulated toxin and liposomal lipid dose are important determinants of PCI-promoted cytotoxicity.

In conclusion, this study demonstrates that PCI is a useful tool to enhance the cytosolic delivery of liposomally encapsulated proteins. By encapsulating saporin in positively charged liposomes (DOTAP-L) or EGFR-targeted PEGliposomes (EGFR-L), the cytosolic delivery of saporin to OVCAR-3 cells and resulting cytotoxicity was strongly enhanced. The use of targeted liposomes (targeting mediated by cationic charge or targeting ligand) appears essential, as the cytotoxicity of saporin in non-targeted PEG-L was not enhanced when compared to free saporin in combination with PCI. Increasing the illumination time decreases the cell viability, which is probably caused by an additional cytotoxic PDT effect. We conclude that PCI is a promising technique for promoting cytosolic delivery of liposomally targeted proteins. In addition to proteins, also other macromolecules like nucleic acids are expected to benefit from this liposomal intracellular targeting approach. Fortunately, although this paper is based on in vitro experimentation, the translation to the in vivo situation is considerable favoured by the recent developments in fibre optics and laser technology which have made it possible to illuminate many sites in the human body.

\section{ACKNOWLEDGEMENTS}

The authors would like to thank the Norwegian Research Foundation for financial support. Dr. Raymond M. Schiffelers is kindly acknowledged for his help with the statistical analysis of the data.

\section{REFERENCES}

1. A. A. Gabizon, H. Shmeeda, and S. Zalipsky. Pros and cons of the liposome platform in cancer drug targeting. J. Liposome Res. 16:175-183 (2006).
2. J. M. Metselaar, E. Mastrobattista, and G. Storm. Liposomes for intravenous drug targeting: design and applications. Mini Rev. Med. Chem. 2:319-329 (2002).

3. R. M. Straubinger, K. Hong, D. S. Friend, and D. Papahadjopoulos. Endocytosis of liposomes and intracellular fate of encapsulated molecules: encounter with a low $\mathrm{pH}$ compartment after internalization in coated vesicles. Cell 32:1069-1079 (1983).

4. J. Huwyler, J. Yang, and W. M. Pardridge. Receptor mediated delivery of daunomycin using immunoliposomes: pharmacokinetics and tissue distribution in rats. J. Phamacol. Exp. Ther. 282:1541-1546 (1997).

5. S. Simoes, J. N. Moreira, C. Fonseca, N. Duzgunes, and M. C. Limade. On the formulation of $\mathrm{pH}$-sensitive liposomes with long circulation times. Adv. Drug Deliv. Rev. 56:947-965 (2004).

6. C. J. Provoda, E. M. Stier, and K. D. Lee. Tumor cell killing enabled by listeriolysin O-liposome-mediated delivery of the protein toxin gelonin. J. Biol. Chem. 278(37):35102-35108 (2003).

7. M. Mandal and K. D. Lee. Listeriolysin O-liposome-mediated cytosolic delivery of macromolecule antigen in vivo: enhancement of antigen-specific cytotoxic T lymphocyte frequency, activity, and tumor protection. Biochim. Biophys. Acta 1563:7-17 (2002).

8. E. M. Stier, M. Mandal, and K. D. Lee. Differential cytosolic delivery and presentation of antigen by listeriolysin O-liposomes to macrophages and dendritic cells. Mol. Pharm. 2:74-82 (2005).

9. E. Mastrobattista, G. A. Koning, L. Van Bloois, A. C. Filipe, W. Jiskoot, and G. Storm. Functional characterization of an endosome-disruptive peptide and its application in cytosolic delivery of immunoliposome-entrapped proteins. J. Biol. Chem. 277:27135$27143(2002)$.

10. T. Kakudo, S. Chaki, S. Futaki, I. Nakase, K. Akaji, T. Kawakami, K. Maruyama, H. Kamiya, and H. Harashima. Transferrinmodified liposomes equipped with a $\mathrm{pH}$-sensitive fusogenic peptide: an artificial viral-like delivery system. Biochemistry 43:5618-28 (2004).

11. A. Hogset, L. Prasmickaite, P. K. Selbo, M. Hellum, B. O. Engesaeter, A. Bonsted, and K. Berg. Photochemical internalisation in drug and gene delivery. Adv. Drug Deliv. Rev. 56:95-115 (2004).

12. K. Berg and J. Moan. Lysosomes as photochemical target. Int. J. Cancer 59:814-822 (1994).

13. F. Stirpe. Ribosome-inactivating proteins. Toxicon 44:371-383 (2004).

14. G. A. Koning, H. W. Morselt, M. J. Velinova, J. Donga, A. Gorter, T. M. Allen, S. Zalipsky, J. A. Kamps, and G. L. Scherphof. Selective transfer of a lipophilic prodrug of 5fluorodeoxyuridine from immunoliposomes to colon cancer cells. Biochim. Biophys. Acta 1420:153-167 (1999).

15. G. Rouser, S. Fkeischer, and A. Yamamoto. Two dimensional then layer chromatographic separation of polar lipids and determination of phospholipids by phosphorus analysis of spots. Lipids 5:494-496 (1970).

16. D. A. Scudiero, R. H. Shoemaker, K. D. Paull, A. Monks, S. Tierney, T. H. Nofziger, M. J. Currens, D. Seniff, and M. R. Boyd. Evaluation of a soluble tetrazolium/formazan assay for cell growth and drug sensitivity in culture using human and other tumor cell lines. Cancer Res. 48:4827-4833 (1988).

17. C. Arigita, L. Bevaart, L. A. Everse, G. A. Koning, W. E. Hennink, J. C. WinkelVan de, M. J. VughtVan, G. F. Kersten, and W. Jiskoot. Liposomal meningococcal B vaccination: role of dendritic cell targeting in development of a protective immune response. Infect. Immun. 71:5210-5218 (2003).

18. D. E. Davies and S. G. Chamberlin. Targeting the epidermal growth factor receptor for therapy of carcinomas. Biochem. Pharmacol. 55:1101-1110 (1996).

19. M. M. Fretz, G. A. Koning, E. Mastrobattista, W. Jiskoot, and G. Storm. OVCAR-3 cells internalize TAT-peptide modified liposomes by endocytosis. Biochim. Biophys. Acta 1665:48-56 (2004).

20. E. Mastrobattista, G. A. Koning, and G. Storm. Immunoliposomes for the targeted delivery of antitumor drugs. Adv. Drug Deliv. Rev. 40:103-127 (1999).

21. P. K. Selbo, K. Sandvig, V. Kirveliene, and K. Berg. Release of gelonin from endosomes and lysosomes to cytosol by photochemical internalization. Biochim. Biophys. Acta 1475:307-313 (2000).

22. K. Berg, A. Dietze, O. Kaalhus, and A. Hogset. Site-specific drug delivery by photochemical internalization enhances the antitumor effect of bleomycin. Clin. Cancer Res. 11:8476-8485 (2005). 
23. K. Berg, P. K. Selbo, L. Prasmickaite, T. E. Tjelle, K. Sandvig, J. Moan, G. Gaudernack, O. Fodstad, S. Kjolsrud, H. Anholt, G. H. Rodal, S. K. Rodal, and A. Hogset. Photochemical internalization: a novel technology for delivery of macromolecules into cytosol. Cancer Res. 59:1180-1183 (1999).

24. P. K. Selbo, G. Sivam, O. Fodstad, K. Sandvig, and K. Berg. Photochemical internalisation increases the cytotoxic effect of the immunotoxin MOC31-gelonin. Int. J. Cancer 87:853-859 (2000).

25. A. Weyergang, P. K. Selbo, and K. Berg. Photochemically stimulated drug delivery increases the cytotoxicity and specificity of EGF-saporin. J. Control Release 111:165-173 (2006).

26. M. Folini, K. Berg, E. Millo, R. Villa, L. Prasmickaite, M. G. Daidone, U. Benatti, and N. Zaffaroni. Photochemical internalization of a peptide nucleic acid targeting the catalytic subunit of human telomerase. Cancer Res. 63:3490-3494 (2003).

27. L. Prasmickaite, A. Hogset, V. M. Olsen, O. Kaalhus, S. O. Mikalsen, and K. Berg. Photochemically enhanced gene trans- fection increases the cytotoxicity of the herpes simplex virus thymidine kinase gene combined with ganciclovir. Cancer Gene Ther. 11:514-523 (2004).

28. A. Hogset, L. Prasmickaite, M. Hellum, B. O. Engesaeter, V. M. Olsen, T. E. Tjelle, C. J. Wheeler, and K. Berg. Photochemical transfection: a technology for efficient light-directed gene delivery. Somat Cell Mol. Genet. 27:97-113 (2002).

29. B. O. Engesaeter, A. Bonsted, K. Berg, A. Hogset, O. Engebraten, O. Fodstad, D. T. Curiel, and G. M. Maelandsmo. PCI-enhanced adenoviral transduction employs the known uptake mechanism of adenoviral particles. Cancer Gene Ther. 12:439-448 (2005).

30. S. B. Brown, E. A. Brown, and I. Walker. The present and future role of photodynamic therapy in cancer treatment. Lancet Oncol. 5:497-508 (2004).

31. D. E. Dolmans, D. Fukumura, and R. K. Jain. Photodynamic therapy for cancer. Nat. Rev. Cancer 3:380-387 (2003). 